
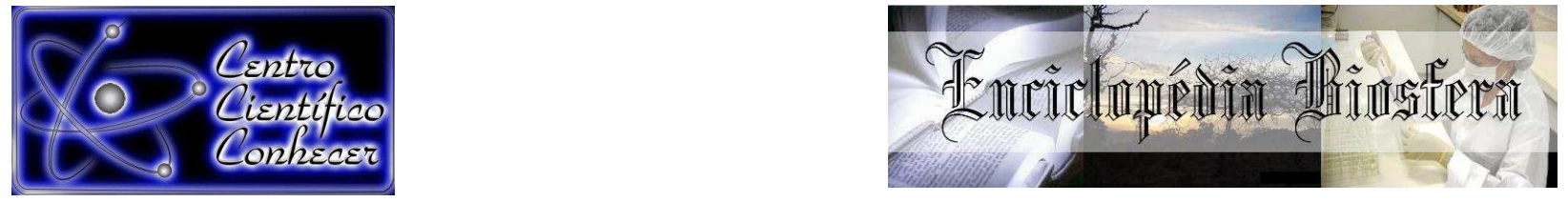

\title{
CONTRIBUIÇÃO TAXONÔMICA AO ESTUDO DO GÊNERO Calliandra BENTH. (LEGUMINOSAE, MIMOSOIDEAE) NO ESTADO DE MATO GROSSO, BRASIL
}

\author{
José Martins Fernandes ${ }^{1}$, Lucirene Rodrigues ${ }^{2}$, José Hypólito Piva ${ }^{3}$; Célia Regina \\ Araújo Soares Lopes ${ }^{4}$ \\ ${ }^{1}$ Professor Doutor da Faculdade de Ciências Biológicas e Agrárias, Campus de Alta \\ Floresta, Universidade do Estado de Mato Grosso (UNEMAT); Herbário da \\ Amazônia Meridional (HERBAM); e-mail: fernanbio@bol.com.br \\ ${ }^{2}$ Professora Mestre da Faculdade de Ciências Biológicas e Agrárias, Campus de Alta \\ Floresta, UNEMAT; HERBAM; \\ ${ }^{3}$ Parataxônomo, Alta Floresta, Mato Grosso; \\ ${ }^{4}$ Professora Doutora da Faculdade de Ciências Biológicas e Agrárias, Campus de \\ Alta Floresta, UNEMAT; Curadora do HERBAM.
}

Recebido em: 03/10/2016 - Aprovado em: 21/11/2016 - Publicado em: 05/12/2016

DOI: 10.18677/EnciBio_2016B_028

\begin{abstract}
RESUMO
O gênero Calliandra Benth. está representado por 142 espécies e possui distribuição nas Américas, sendo que 74 estão representadas no Brasil e apenas cinco são conhecidas para o estado de Mato Grosso. O gênero é caracterizado por apresentar folhas bipinadas sem nectários extraflorais, androceu polistêmone e monadelfo, e fruto legume com deiscência elástica a partir do ápice. O objetivo do trabalho foi fazer o estudo taxonômico de Calliandra surinamensis Benth. considerada como nova ocorrência para Mato Grosso, além de uma chave para identificação das espécies conhecidas para o estado. Foi realizado entre junho e agosto de $2016 \mathrm{com}$ a realização de diagnose morfológica da espécie no Herbário da Amazônia Meridional (HERBAM), localizado na Universidade do Estado de Mato Grosso, Campus de Alta Floresta. A espécie foi coletada no município de Paranaíta e caracterizada como arvoreta, folhas com exatamente 1 par de pina, pecíolo 0,6-1,7 cm compr.; foliólulos 7-13 pares por pina, 0,9-1,5x0,5-0,6 cm, lanceolados a romboides. O trabalho reforça a ampliação de quatro para cinco espécies de Calliandra para a Flora Matogrossense.
\end{abstract}

PALAVRAS-CHAVE: Calliandra surinamensis, Flora Matogrossense, Tribo Ingeae.

\section{TAXONOMIC CONTRIBUTION TO GENUS STUDY Calliandra BENTH. (LEGUMINOSAE, MIMOSOIDEAE) IN MATO GROSSO STATE, BRAZIL}

\footnotetext{
ABSTRACT

The genus Calliandra Benth is represented by 142 species and has distribution in the Americas, and 74 are represented in Brazil and only five are known to the state of Mato Grosso. The genus is characterized by having bipinnate leaves without extrafloral nectaries, androecium polistêmone and monadelfo and fruit legume with elastic dehiscence from the apex. The objective was to make the taxonomic study of Calliandra surinamensis Benth. considered as a new occurrence for Mato Grosso, as well as a key to identify the species known to the state. The study was conducted between June and August of 2016 with the completion of morphological diagnosis of ENCICLOPÉDIA BIOSFERA, Centro Científico Conhecer - Goiânia, v.13 n.24; p.315 2016
} 
the species in the Herbarium of the Southern Amazon (HERBAM) located at the State University of Mato Grosso, Campus of Alta Floresta. The species was collected in the city of Paranaíta and characterized as small tree, leaves with exactly one pair of pina, petioles 0,6 to $1,7 \mathrm{~cm}$ long; leaflets $7-13$ peer pina, $0,9-1,5 \times 0,5-0,6 \mathrm{~cm}$, lanceolate to rhomboid. The work reinforces the expansion from four to five species of Calliandra for Flora Matogrossense.

KEYWORDS: Calliandra surinamensis, Flora Matogrossense, Tribe Ingeae.

\section{INTRODUÇÃO}

O gênero Calliandra foi estabelecido por Bentham (1844) e inclui espécies da subfamília Mimosoideae com androceu polistêmone e monadelfo que possuem um tipo de legume caracterizado pela deiscência longitudinal elástica a partir do ápice e valvas com margens espessadas (SOUZA \& QUEIROZ, 2004). Estudo recente da filogenia de Calliandra Benth. (Leguminosae: Mimosoideae) com base em marcadores moleculares nucleares e plastidiais considera o gênero como monofilético com a inclusão do gênero Guinetia L.Rico \& M.Sousa, que possui apenas uma espécie e que agora pertence ao gênero Calliandra ( $C$. tehuantepecensis (L. Rico \& M. Sousa) E.R. Souza \& L.P. Queiroz), com ocorrência no México (SOUZA et al., 2013).

Calliandra é caracterizado como árvores, arbustos, subarbustos ou ervas; ramos inermes; gemas peroladas e catáfilos ausentes ou presentes; estípulas persistentes ou caducas; folhas bipinadas, microfilídias ou macrofilídias, pinas 1muitos pares; nectários ausentes; foliólulos 1-muitos pares por pina; inflorescências com unidades umbeliformes ou capituliformes reunidas em fascículos ou isoladas; brácteas caducas ou persistentes; flores homomórficas ou heteromórficas, 4-6-mera; androceu monocolor ou bicolor, tubo incluso ou exserto; disco nectarífero presente ou ausente; frutos legumes, plano compressos, margens estreitas ou expandidas, lenhosos com deiscência ativa; sementes monocolores, testa óssea e pleurograma geralmente presente (BARNEBY, 1998).

O gênero Calliandra Benth. esta representado por 142 espécies e possui distribuição desde os Estados Unidos até o Uruguai, com maior diversidade no Nordeste do Brasil, com cerca de 66 espécies, principalmente em áreas de campo rupestre (BARNEBY, 1998; LEWIS \& RICO ARCE, 2005; SOUZA et al., 2013).

No Brasil, o gênero está representado por 74 espécies com 59 endêmicas, com centro de diversidade na Caatinga (55 espécies), no Cerrado (22 espécies) e na Amazônia (11 espécies), enquanto que a Mata Atlântica possui apenas sete espécies, o Pampa com duas espécies e o Pantanal sem nenhuma espécie. Os estados com maior riqueza em espécies são Bahia (49 espécies) e Minas Gerais (19 espécies), Mato Grosso tem apenas quatro espécies citadas para o estado (SOUZA, 2016).

As espécies do gênero apresentam grande potencial ornamental, destacandose C. brevipes Benth., C. harrisii (Lindl.) Benth., C. inaequilatera Rusby e C. tweedii Benth., são plantadas isoladas ou formando conjuntos, mas o efeito ornamental mais notável é como cerca viva (LORENZI \& SOUZA, 2008; CORADIN et al., 2011; MILANI et al., 2014). Várias outras espécies apresentam grande potencial ornamental, inclusive nativas no Brasil como $C$. dysantha Benth., $C$. sessilis Benth. C. surinamensis Benth. e C. laxa (Willd.) Benth., que não estão ameaçadas de extinção e que possuem ampla distribuição geográfica. 
Como medicinal a espécie $C$. fernandesii Barneby é usada entre moradores de comunidade rurais da Serra do Passa Tempo, Estado do Piauí, para o tratamento de problemas no sangue, menstruação, espinha, manchas na pele e problema urinários (ALMEIDA-NETO et al., 2015). Este trabalho teve por objetivo realizar o estudo taxonômico da espécie $C$. surinamensis Benth., considerada como nova ocorrência para a flora de Mato Grosso, além de oferecer uma chave para identificação das espécies do gênero Calliandra para o estado.

\section{MATERIAL E MÉTODOS}

Foram analisadas duas exsicatas da espécie de $C$. surinamensis, totalizando sete ramos férteis. As coletas foram realizadas no município de Paranaíta, extremo Norte do Estado de Mato Grosso e depositada no Herbário da Amazônia Meridional (HERBAM), localizado na Universidade do Estado de Mato Grosso, Campus de Alta Floresta. O HERBAM foi registrado na Rede Brasileira de Herbários em 2007 (SOARES LOPES, 2015) e mantém aproximadamente 14.000 exsicatas depositadas.

A chave para identificação das espécies de Calliandra em Mato Grosso foi elaborada considerando-se a riqueza apresentada por SOUZA (2016) e, como nova ocorrência o trabalho de FERNANDES et al. (2015); as informações morfológicas foram baseadas nos trabalhos de BARNEBY (1998) e FERNANDES (2011), além dos espécimes do gênero depositados no HERBAM. Para a descrição morfológica de $C$. surinamensis baseou-se na terminologia disponível em FERNANDES \& GARCIA (2014).

\section{RESULTADOS E DISCUSSÃO}

A coleção do HERBAM mantém exsicatas de duas espécies de Calliandra, dentre elas, $C$. surinamensis, considerada como nova ocorrência para a flora de Mato Grosso. A espécie foi coletada no município de Paranaíta (9¹4'29"S, 5653'04"W 0914'18,089"S, 5954'12,16”W), Norte do Estado, a partir da intensificação de expedições científicas realizadas na região.

As quatro espécies com ocorrência conhecida para Mato Grosso são: $C$. dysantha Benth., C. laxa (Willd.) Benth., C. longipes Benth. e C. parviflora Benth. As características consideradas importantes para a diferenciação das espécies no Estado são hábito, folha, inflorescência e flor.

Chave para identificação das espécies de Calliandra em Mato Grosso

1. Pina 1 par em todos os ramos.

2. Foliólulos 1/1/2 par por pina, obovados ou elípticos; pedúnculo $6-24 \mathrm{~cm}$ compr.

2. Foliólulos 7-13 pares por pina, lanceolados a romboides; pedúnculo 1,2-1,6 $\mathrm{mm}$ compr.

C. surinamensis

1. Pina 2-36 pares em todos os ramos.

3. Foliólulos 30-49 pares por pina, 0,4-0,8 mm largura

3. Foliólulos 8-29 pares por pina, 1,7-8 mm largura

C. parviflora

4. Subarbustos; pedúnculo bracteado; flores homomórficas, cálice 4-8 mm compr.; corola 9-15 mm compr.; androceu 44-106 estames .. C. dysantha

4. Arbustos ou árvores; pedúnculo ebracteado; flores dimórficas, cálice 1,4-3 mm compr.; corola 4,5-8,5 mm compr.; androceu 8-18 estames .... C. laxa 
Calliandra surinamensis Benth., London J. Bot. 3: 105. 1844. Sinônimo: Calliandra tenuiflora Benth., Trans. Linn. Soc. London 30(3): 547. 1875.

(Figura 1)

Arvoretas $5 \mathrm{~m}$ alt.; estípulas $4-7 \times 1-2 \mathrm{~mm}$, lanceoladas a estreitamente ovadas, tomentosas, persistentes; folha com exatamente 1 par de pina, pecíolo 0,6-1,7 cm compr., canaliculado, tomentoso, raque das pinas 3-6,5 cm compr., canaliculada, vilosa; foliólulos 7-13 pares por pina, 0,9-1,5×0,5-0,6 cm, lanceolados a romboides, base oblíqua, ápice agudo, face abaxial glabra a esparsamente serícea, face adaxial glabra, margens esparsamente serícea. Unidades de inflorescências axilares, umbeliformes; pedúnculo 1,2-1,6 mm compr., tomentoso, 1-2-bracteado, 1x1 mm, ovadas, glabras; flores 18-24 por unidade, receptáculo 1-2 mm de diâmetro brácteas 0,6-0,8 $\times 0,5-0,7 \mathrm{~mm}$ lanceoladas, faces glabras, margens esparsamente serícea, pedicelos 0-0,2 mm compr.; cálice 5-6-mera, 3,2-4 mm compr., campanulado, esparsamente puberulento externamente; corola 5-mera, 8-9 $\mathrm{mm}$ compr., estreitamente campanulada, esparsamente serícea; androceu $4-5 \mathrm{~cm}$ compr., parte basal esbranquiçada e terminal avermelhada, 18-28 estames, tubo 2-2,3 cm compr., exserto; ovário pubescente. Frutos não observados.

Comentários: No Brasil C. surinamensis assemelha-se a $C$. sessilis Benth. por apresentar folhas com exatamente um par de pina, foliólulos não ultrapassando 14 $\mathrm{mm}$ de largura, no entanto, $C$. Surinamensis diferencia-se por apresentar pedúnculo entre 7-20 mm de comprimento, foliólulos entre 5-19 pares por pina, raramente 17 pares, enquanto que $C$. Sessilis possui pedúnculo entre 0-2 $\mathrm{mm}$ de comprimento, foliólulos entre 18-39 pares por pina (BARNEBY, 1998).

Segundo BARNEBY (1998), C. surinamensis também apresenta afinidades com C. purpurea (L.) Benth., que ocorre na América Central, pelo formato e largura dos foliólulos, mas difere por apresentar no mínimo oito pares de foliólulos por pina e tegumento da semente sem pleurograma, enquanto que $C$. purpurea apresenta entre 3-7 pares de foliólulos por pina e tegumento com pleurograma. Os caracteres da espécie citados pelos autores na última revisão taxonômica foram encontrados no material coletado no município de Paranaíta, Norte de Mato Grosso.

A espécie ocorre na Venezuela, Equador, Colômbia, Peru, Guiana Francesa, Guiana Inglesa e Brasil (BARNEBY, 1998). No Brasil a espécie ocorre nos Estados do Acre, Amazonas e Pará, em floresta ciliar ou de galeria, floresta de igapó, floresta de terra firme e em disjunções de Cerrado, sob domínio fitogeográfico da Amazônia (SOUZA, 2016). BARNEBY (1998) também cita para os Estados do Maranhão, Roraima e Rondônia.

Segundo BONADEU \& SANTOS (2013) em estudo das espécies de Ingeae na Floresta Nacional de Caxiuanã, no Estado do Pará, citaram que $C$. surinamensis foi coletada em área antropizada no município de Melgaço e é um novo registro para a Flora de Caxiuanã e floresce e frutifica nos meses de abril, novembro e dezembro. FERNANDES et al. (2015) fizeram a primeira citação da espécie para a flora do Estado de Mato Grosso, coletada em área de mata ciliar no município de Paranaíta.

Material examinado: BRASIL. MATO GROSSO: Paranaíta, Usina Hidrelétrica São Manoel, 29.V.2009, fl., C. R. A. Soares-Lopes, J. H. Piva, J. A. Rocha-Filho, L. Rodrigues, J. A. M. Melo e F. F. Cabral 2281 (HERBAM); margem do Rio Teles Pires, 03.III.2011, fl., L. Rodrigues, I. L. Ribeiro, R. C. Santos 140 (HERBAM). 

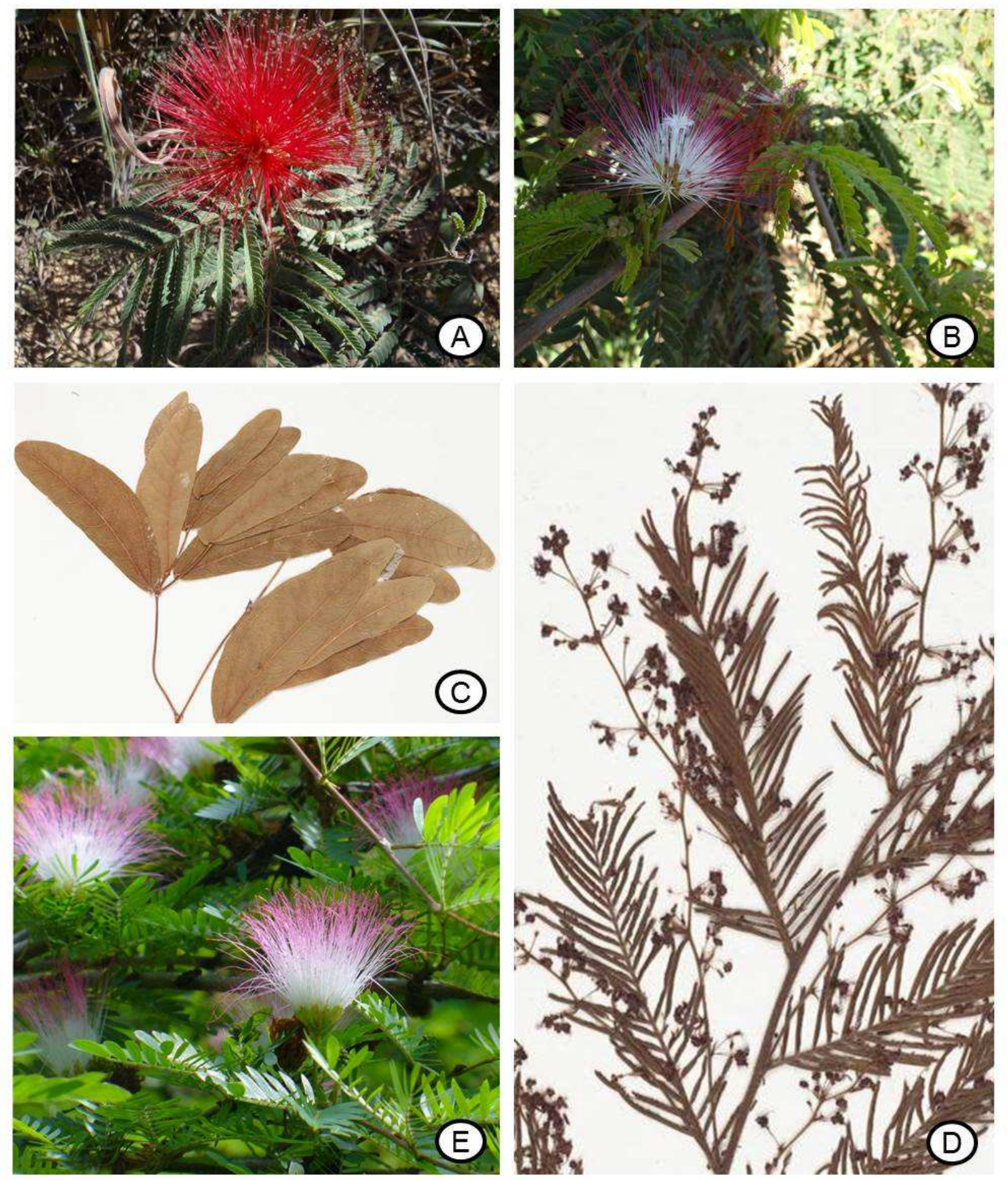

FIGURA 1. Espécies do gênero Calliandra no Estado de Mato Grosso: A) Folhas e inflorescência de $C$. dysantha, B) Ramo com folhas e inflorescências de $C$. laxa, C) Folhas de $C$. longipes, D) Ramo com folhas e inflorescências de $C$. parviflora, E) Ramo com folhas e inflorescências de $C$. surinamensis. Fotos: A (FERNANDES, 2012) e B (FERNANDES, 2012), C e D (New York Botanic Garden, 2016) e E (SCOTT ZONA, 2008). 


\section{CONCLUSÕES}

O trabalho reforça a ampliação de $C$. surinamensis para o Estado de Mato Grosso, totalizando cinco espécies com ocorrência na região. A espécie foi coletada durante a intensificação de expedições na região de Alta Floresta.

Provavelmente com a intensificação de mais coletas no Estado, bem como a análise das coleções botânicas ou coletas depositadas em coleções de outros estados, possivelmente novas ocorrências sejam encontradas para o Mato Grosso.

\section{REFERÊNCIAS}

ALMEIDA-NETO, J. R.; BARROS, R. F. M.; SILVA, P. R. R. Uso de plantas medicinais em comunidades rurais da Serra do Passa Tempo, Estado do Piauí, Nordeste do Brasil. Revista Brasileira de Biociências, v. 13, n. 3, p. 165-175, 2015.

BARNEBY, R. C. Silk Tree, Guanacaste, Monkey's Earring. A Generic System for the Synandrous Mimosaceae of the Americas: part III. Calliandra. Memories of The New York Botanical Garden v. 74, 223p., 1998.

BONADEU, F.; SANTOS, J. U. M. Contribuição ao conhecimento dos gêneros da tribo Ingeae ocorrentes em uma Floresta Nacional da Amazônia Brasileira. Rodriguésia, v. 64, n. 2, p.321-336, 2013.

CORADIN, L.; SIMINSKI, A.; REIS, A. Espécies nativas da flora brasileira de valor econômico atual ou potencial: plantas para o futuro - região Sul. Brasília: MMA, 934p., 2011.

FERNANDES, J. M. Ingeae Benth. (Leguminosae, Mimosoideae) no Estado de Minas Gerais, Brasil: taxonomia, morfoanatomia de nectários extraflorais e padrões de distribuição geográfica. Tese de Doutorado, 313f. Universidade Federal de Viçosa, Viçosa, Minas Gerais. 2011.

FERNANDES, J. M.; SOARES-LOPES, C. R. A.; RIBEIRO, R. S.; SILVA, D. R. Leguminosae no acervo do Herbário da Amazônia Meridional, Alta Floresta, Mato Grosso. Enciclopédia Biosfera, v. 11, n. 21, p.2272-2293, 2015.

FERNANDES, J. M; GARCIA, F. C. P. Expanding the description of Bionia bella Mart. ex Benth. (Leguminosae, Papilionoideae). Acta Botanica Brasilica, v. 28, n. 2, p.141-146, 2014.

LEWIS, G. P.; RICO ARCE, M. L. Tribe Ingeae. In: LEWIS, G. P.; SCHRIRE, B. D.; MACKINDER, B. A.; LOCK, J. M. Leguminosae of the World. Royal Botanic Gardens, Kew, pp.193-213, 2005.

LORENZI, H.; SOUZA, H. M. Plantas ornamentais no Brasil: arbustivas, herbáceas e trepadeiras. 4 ed. Nova Odessa, SP: Instituto Plantarum, 1088p., 2008. 
MILANI, J. E. F.; OLIVEIRA, T. W. G.; BARBIERI, G. Potencial biotécnico de espécies vegetais para recuperação de cursos d'água no Estado de Santa Catarina. Enciclopédia Biosfera, v. 10, n. 18, p.2316-2326, 2014.

SOARES LOPES, C. R. A. Herbário da Amazônia Meridional. Unisanta Bioscience, v.4, n.6, p.36-39, 2015.

SOUZA, E. R.; LEWIS, G. P.; FOREST, F.; SCHNADELBACH, A. S.; BERG, C. V. D.; QUEIROZ, L. P. Phylogeny of Calliandra (Leguminosae: Mimosoideae) based on nuclear and plastid molecular markers. Taxon, v. 62, n. 6, p.1201-1220, 2013.

SOUZA, E. R.; QUEIROZ, L. P. Duas novas espécies de Calliandra Benth. (Leguminosae - Mimosoideae) da Chapada Diamantina, Bahia, Brasil. Revista Brasileira de Botânica, v. 27, n. 4, p.615-619, 2004.

SOUZA, E. R. Calliandra in Lista de Espécies da Flora do Brasil. Jardim Botânico do Rio de Janeiro. Disponivel em: <http://floradobrasil.jbrj.gov.br/jabot/floradobrasil/FB22845. Acessado em: 26 de julho de 2016. 